\title{
Adaptive Ecosystem-Integrated Technology into the Curriculum
}

\author{
Patrícia Lupion Torres, Katia Ethiénne Esteves dos Santos, \\ Raquel Pasternak Glitz Kowalski, Marilda Aparecida Behrens
}

PPGE, PUCPR, Curitiba, Brazil

Email: patorres@terra.com.br

Received 27 October 2015; accepted 19 January 2016; published 22 January 2016

Copyright (C) 2016 by authors and Scientific Research Publishing Inc.

This work is licensed under the Creative Commons Attribution International License (CC BY). http://creativecommons.org/licenses/by/4.0/

(c) (i) Open Access

\section{Abstract}

Innovation has taken hold of the everyday actions related to fun, work, education, among others, influencing cultural movements, political actions, economic and social. This new context brings outstanding requirements, especially regarding the preparation of children and young people to face the challenges ahead in a lifetime. Although there is no easily verifiable relationship between innovation and improvements in education, the existence of different elements such as: digital resources, enhancement of learning styles, applying knowledge in real situations, the interpretation of data and texts that suggest new ways of organizing the curriculum, which can offer the educational environment to improve the quality of teaching-learning process. This document aims to present a digital adaptive ecosystem, which enables: differentiated learning, motivation through gamification features, monitoring of performance data of students and the possibility of changing teaching strategies according to individual or group needs. The appropriation of technology in school culture can generate significant changes and pedagogical innovation, but such changes only occur when there is also a curriculum change. Thus, the curriculum as a whole incorporates the language of the digital world. They gave subsidy to that document Lévy (1993), Martin-Barbero (2002), Libâneo (1985), Santos (2012) among others. The innovative adaptive ecosystem presented here brings in its design an approach that is premised on the development of the autonomy of the student in relation to its individual plan ahead learning the formal curriculum, in addition to offering the technological resources for teachers that allow closer monitoring of each student, its construction process, knowledge and the acquisition of different skills. We attempted to verify with data collection which the perception of those involved in the process of training of teachers in relation to curriculum integration and technology. In a qualitative approach, questionnaires were conducted with the five trainers for adaptive ecosystem in its holdings showed how technology can be integrated into the curriculum, gradual and effective manner, through different actions. 


\section{Keywords}

\section{Integration, Curriculum, Education, Learning, Technology, Adaptive Ecosystem}

\section{Introduction}

The studies of Lévy (1993) present the idea of "cognitive ecology" on intelligence or cognition result of complex networks, where they interact a lot of human, biological and technical authors.

In this inter-relationship, it is vital to have an ongoing involvement of individuals that make up the process. This community is not only constituted by humans, for the techniques of communication and processing of representations also play an important role which has connections Lévy (1993). The "cognitive ecology" could then be summarized as the study of techniques and collective dimensions of cognition, which combines complex networks.

For being a theorist of communication in Latin America, Martin-Barbero (2002) takes up the discussion of "ecosystem" relating to their area of study, but to the degree necessary to relate communication to education:

The relationship between education and communication, the latter is almost always reduced to a purely instrumental dimension. It left out what is precisely strategic thinking, that is the inclusion of education in complex communication processes of modern society, talking or otherwise, think of the communications ecosystem that is diffuse and decentered educational environment in which we are immersed. A diffuse environment because it is made up of a mix of languages and knowledge circulating in different media devices, but dense and intrinsically interconnected; and decentered by the relationship with the two centers: School book and that several centuries organize the educational system (Barbero, 1998: p. 215).

This communication ecosystem ratio Barbero and cognitive ecosystem show that the terms discussed by Lèvy and Barbero are intersected, because the assumptions are intrinsic.

In the evolution of their studies, Barbero (2002) mentions that "the school should think less in ideological and moral effects of media and more in communicative ecosystems, which are formed by the set of languages, written, representations and narratives that alter perception.”

At this point, the concept of culture can be analyzed with a more contemporary look when it reveals the integration of science and technology. These elements to be inserted to everyday life can influence several environments including education providing the opportunity to carry up an education to human beings in full.

Ecosystem talking brings the complexity of this historical moment, in the second decade of the twenty-first century, we are living in a fluid society, dynamic and innovative. The technology shows us an opportunity to perceive the diversity of thoughts, ideas, information and knowledge.

We can see then that should also be taken into consideration the need to respect that there are different ways and rhythms of learning and especially the "teach" has to be reviewed in order to provide the diversity of opportunities needed for this century.

The term "ecosystem" happens to be adopted at this time to be able to add to the actors of the educational process (managers, teachers and students) technologies to teaching and learning strategies. This proposal allows the educational actions to develop discoveries, reformulations, creations and constant innovations.

The interrelationship proposed by Lévy (1993) should be fundamental in this ecosystem involving school community, managers, teachers and students enabling the reorganization of physical spaces, the inclusion of family members and the search for integral development (academic, social-emotional and cognitive) student to occur the inclusion of technology in their school environment.

This front posture education allows to bring the new technology educational environment occurs special attention to basic issues such as:

- In the classrooms are presented students with different interests;

- There are talents that should be valued and expanded;

- Appear behavioral difficulties and learning to be settled and not ignored;

- The teachers have different skills in relation to areas of knowledge;

- Digital inclusion happens to effectiveness; 
- The development of the role and autonomy become focus of learning.

The ecosystem view began with the vision of the universe as a mechanical approach system blocks (Capra, 1999). The current world according to holistic view also unifies the ecological vision that recognizes the interdependence of all phenomena. This integrated approach looks at the universe as a network of events that are fundamentally interconnected and interdependent. The web of life recognizes ecology as intrinsic value of all living beings, and human beings as process drivers. Capra further supports stating:

Reconnect with the web of life means building, nurturing and educating sustainable communities, in which we can meet our aspirations and our needs without diminishing the chances of future generations. To accomplish this, we need to understand studies of ecosystems, understand the basic principles of ecology, being ecologically literate or "co-literate” (Capra, 1999: p. 231).

Understanding ecosystems means learning how to live sustainably. The wisdom of nature is the essence for an integrated, organized and complex learning. The technology can mediate this process in order to favor a holistic view of life and education.

\section{Complex Ecosystem}

In addressing up items as latent intention is to have access to an ecosystem consists of a series of didactic and pedagogical strategies, individualized activities capable of respecting the different rhythms of learning and knowledge that each bring their experiences, as well as create opportunities for autonomy by means of individual learning plans, and the creation of various choices along the knowledge acquisition process.

For this transformation of existing educational structures, the effective participation of teachers becomes even more necessary for such a relationship of trust and partnership between the parties is the basis for a shared leadership and the development of autonomy. A digital ecosystem developed from the idea of offering different opportunities for teaching and learning, through, videos, images, games, graphics, text, interactive content, issues, among others, thereby contributing to the advancement in building knowledge.

The use of Information and Communication Digital Technologies (TDICs) and in a particular way the way that they are embedded in daily life requires a paradigm shift in relation to the respect and appreciation of learning styles. This change enables and promotes individualized and targeted situations in this way, the teacher can receive information about your own learning style and to know the preferences of their students in order to develop the necessary complementarities in addition to getting elements that serve to differentiate your teaching practice. In his studies of learning styles Felder (1993) argues that:

Learning styles can be defined as the internal characteristics or the individual preferences of learners as receive and / or process information. These styles are not always aware, also exert significant influence in the strategies used to learn (Felder, 1993: p. 286).

Knowing the different styles and offer resources able to expand them is important, since it can explain the "why" of certain teaching strategies achieve their goals and not others. To Cavellucci (2006: p. 10-11) learning styles are ways that every student, regardless of age, used to build knowledge. Studies of Lindemann (2008) assist in the search for individual valuation of preferences and styles, thus expanding the learning of each student possibilities.

This identification plays a crucial role as it "promotes a link between education and the ways in which students prefer to learn and, if so, students demonstrate better results and a stronger desire to learn” (Given, 2002: p. 175).

Dottrens (1975) converses with the prospect that "the student move means everything the student is: their skills, capabilities, skills, personality traits, interests, motivations, affections, problems and needs”. It becomes a unique teaching-learning process.

In addition to the learning styles should take into account the need for a more assertive proposal regarding individual characteristics of each and that these are based on determinant factors such differences as genetic factors, environmental factors and the combination of earlier that interfere with the ability to learn or perform a cognitive/motor activity.

Regardless of gender and age, each individual has an infinite number of differences, which are revealed in the educational processes, requiring the didactic-pedagogic proposal offering opportunities for each student to benefit the school environment and their ability to learn and also teach. 
It is noteworthy that although it is not something effectively accepted, but that has been widely studied, there is a tendency to "the use of personalized teaching has proved to be the most appropriate methodological strategy for different students to benefit from the maximum and best learning” (Pimentel, 1998).

\section{Adaptive Ecosystem}

Starting from the presented premise, in relation to learning and their specificities, it is necessary a restructuring of the current model of education in which a teacher teaches classes for an average class of thirty students, or more, hardly managing to meet all with same quality. This reality makes necessary a new proposal based on the use of learning technologies (hardware and applications that offer from various content, such as data analysis) and a new role teachers view teaching.

With the division of the class for needs or talents, it is possible to develop multiple skills simultaneously and offer different approaches on various topics according to the specific needs of each student.

Upon reflecting on this customization GarcíaHoz (1977), the main driver of this type in Spain, shows that this characteristic to individualize could meet three major concerns: teaching efficiency, democratization of society and of educational institutions and special attention to human dignity.

Researchers from personalized instruction have advanced in the settings, they see changing with the passage of time and the constant innovations that all are subject. Some advantages of this paradigm shift have been described and are summarized in the Table 1.

A more personalized service, encourages observation, self assessment and to cooperation with colleagues, in performing the pedagogical work between pairs, or in groups, developing a sense of cooperation and socialization, to the extent that there is the allocation of responsibilities each one of the students.

Therefore, "the teacher's role is more effective on the question of the direction of cooperation activities, always presenting a clear division of roles and tasks of each member of the group” (Santos, 2012: p. 16).

It is believed that a more contemporary approach in the education sector provides self-motivation, as the student to receive the educational opportunities to choose from, perform or create new activities (videos, bring pictures, podcasts, etc.), in areas defined by the teacher or by himself, and analyzing the results of their performance, tend to develop feelings of confidence and motivation.

This approach, facilitated by the use of technologies, brings in its current structure elements such as inserting playing characteristics-gamification-to the school environment. It is understood that the game has a great educational value and can be an ally in the construction of knowledge. An example of game use of incentive in education is the Kodu Game Lab (2014) (http://www.kodugamelab.com/) where students can create and share games created collaboratively through projects. Factors such as the score, achievements, rankings, among others, are related to the challenges or problem situations can increase the cognitive, social and emotional development, making it more enjoyable and motivating learning.

The idea of offering different levels of challenges, but these appropriate participants, quoted by Silverman (1983), reduces the failure trend, and functions as a way to achieve "success".

Such a complex ecosystem with differential characteristics requires a new proposition based on evolving technology that enables, for example, the use of algorithms that can record the performance of students through its successes and failures, their actions while using applications, Besides providing individual study plans according

Table 1. Customized education.

The attitude of the teacher against the student, a small group or the whole class has different effects

The attitude of teachers

The possibility of offering customization of learning
When driving up to a single student, the intervention tends to be effective and has a much more profound and lasting effect than directed to the class or even a group. In analyzing the current situation of schools is noticed that the larger the group involved, the lower the probability of intervention is appropriate to each of the students, taking its toll, often close to zero.

Tends to reduce the difference between the levels of learning presented by his students at the beginning of a given school year, for to be able to make a proposal that meets the different levels of learning.

Allow the student to remain less time without challenging activities, as usually with the insertion of technologies can be presented several practical situations on the subject matter. 
to the ease of each.

In this context the teaching and learning can rely on new media, i.e. those that are inserted into the computing environment and are part of everyday life of people, such as videos, images, podcasts, digital texts, interactive activities, games, among others, bringing the effective gains knowledge acquisition.

In proposing a complex ecosystem that involves the school community, the inclusion of technologies, diverse content, data analysis and teaching strategies, it has been based on the idea of a new learning experience for the generation that is now in room class can make use of technology to communicate, seek information, entertain, insert themselves in digital culture in order to also build it.

Integrate technology into the curriculum, besides having a "what" of technological modernization, gives opportunity to new didactic and pedagogical practices are built from the scope of teacher-teacher relations, teacher-student, student-student and the entire school community.

\section{The Aprimora as Ecosystem Adaptive}

The Aprimora Elementary School is a multiplatform application based on adaptive ecosystem concept, according to which the route traveled by the corresponding student to their cognitive development and learning pace of each student. Figure 1 shows the elements that make up this ecosystem and its correlations.

The Aprimora elementary school integrates technological resources to curricula aimed at the development and competences and skills in Portuguese Language (Figure 2) and Mathematics (Figure 3) organized in levels, grids, skills and modules, via an in app this mechanism that indicates the learning path to be followed, according to the student's proficiency.

The more than thirty-two thousand questions divided into modules evaluate student performance in a particular skill: the correct answers allow proceed to subsequent issues and incorrect answers present, based on the indicated alternative, an additional set of proposals that take to reflect on the reply, content review, correct their thinking and assimilate the concept addressed. In line with the concept of gamification, in Figure 4, whenever you finish an activity, students receive scores and awards that serve as the fostering of skills. The teacher can set for each student or group of students, the teaching strategy that defines the content to be studied and create combinations of existing options, supporting teachers in planning their lessons, from freer to more structured, according to your goal.

The reports (Figure 5) allow the teaching view the performance of the class or each student individually, the number of questions answered by module, the amount of hits and misses, the average response time, among other elements that can be registered by the application, as of actions of students. The teacher can also follow, in real time, the development of activities, allowing you to always help students to realize that this presents difficulties in content or stimulate it if reaching the goals.

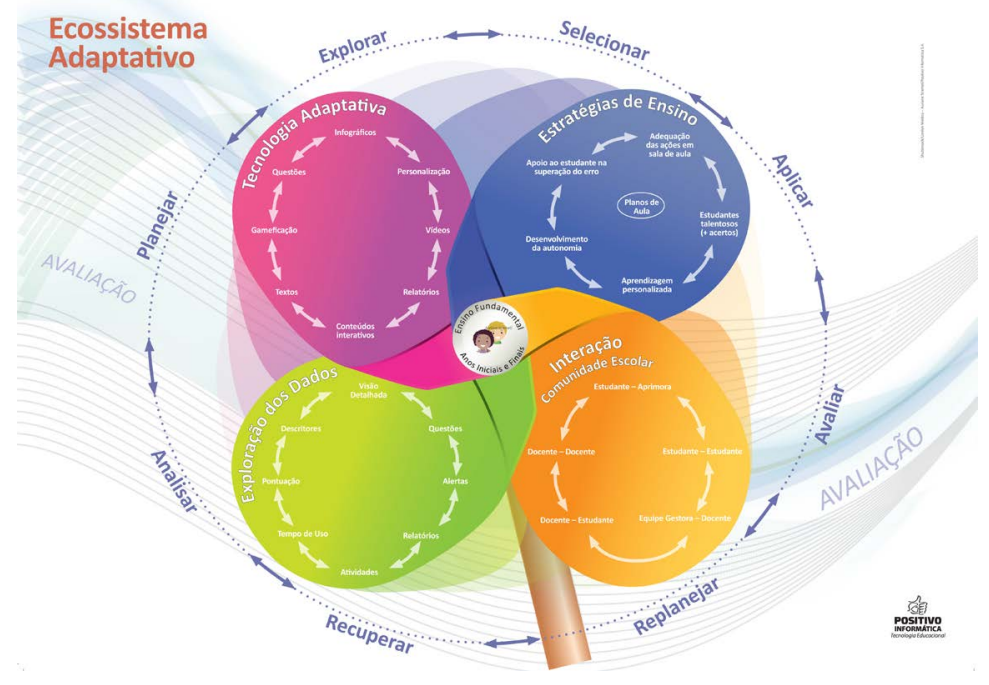

Figure 1. Adaptive ecosystem. Source: Aprimora Elementary School. 


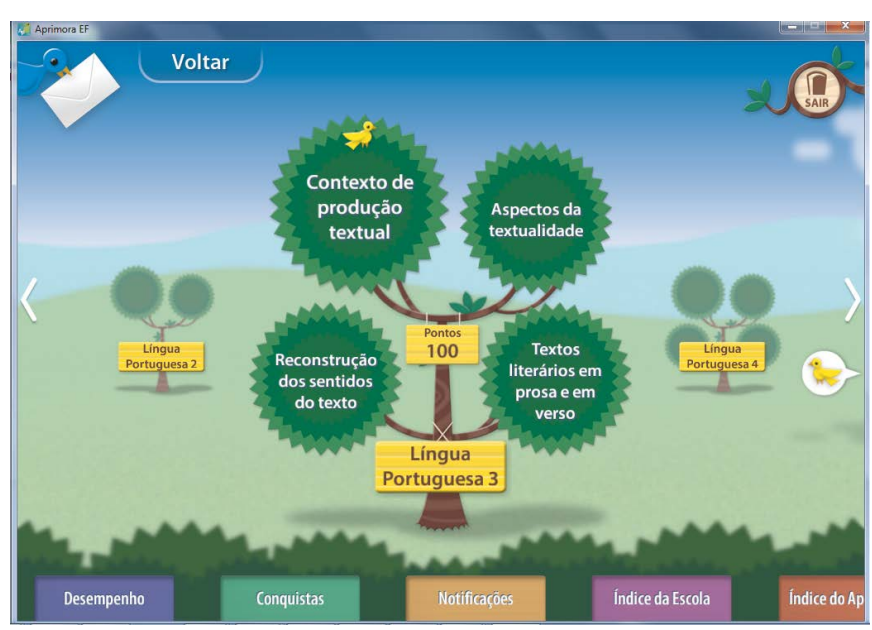

Figure 2. Portuguese language. Source: Aprimora Elementary School.

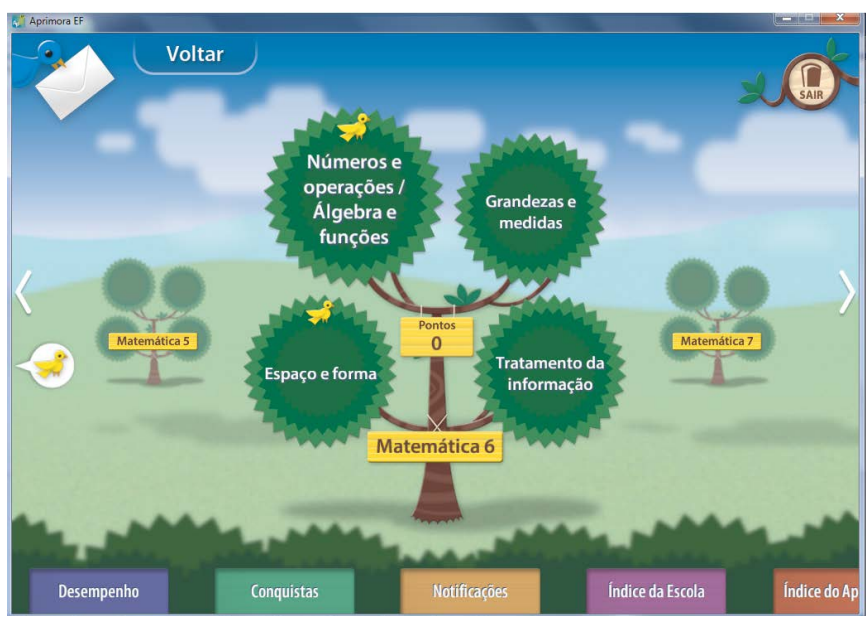

Figure 3. Mathematics. Source: Aprimora Elementary School.

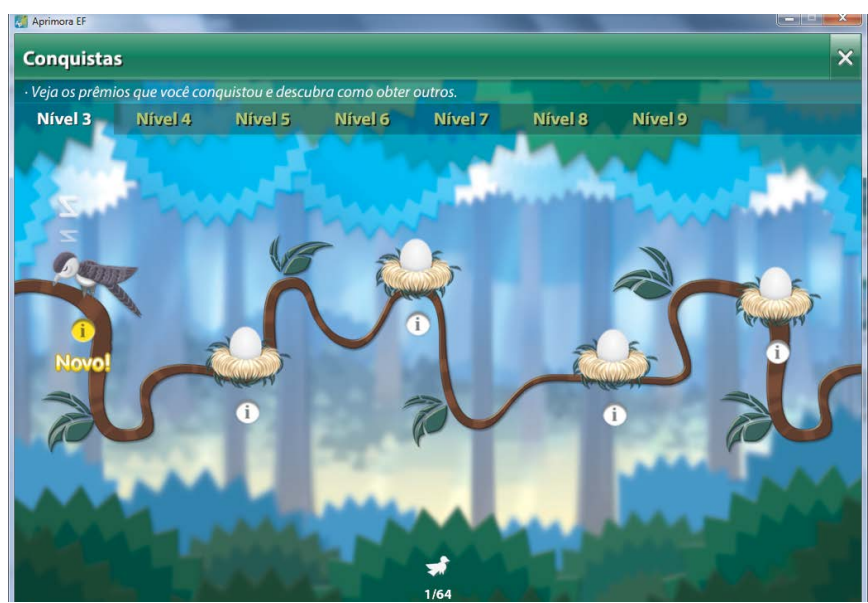

Figure 4. Application screen. Source: Aprimora Elementary School.

The student has access to reports which show the number of unanswered questions and the percentage of hits and misses, which allows a redesign of their study strategies. The Aprimora Elementary School can be accessed in online mode or in offline mode in local network. 

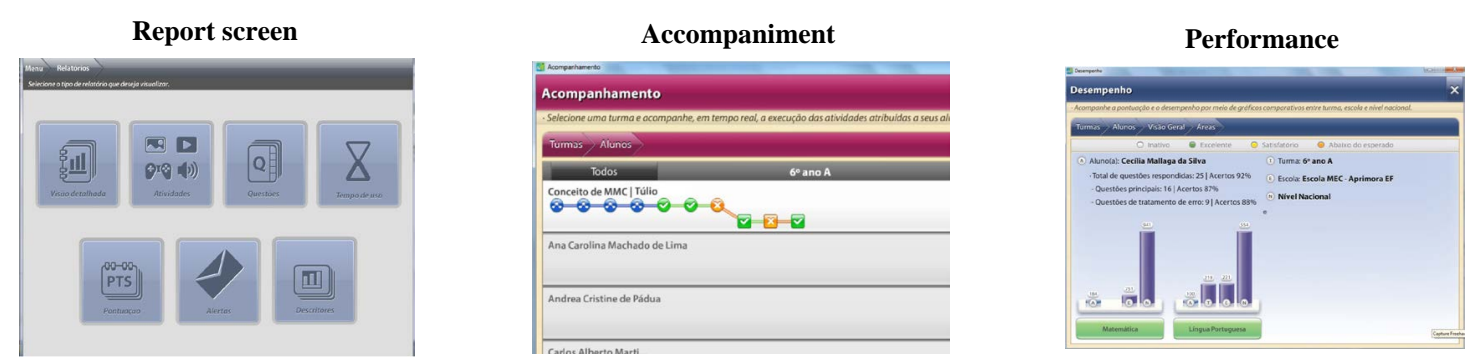

Figure 5. Application features. Source: Aprimora Elementary School.

\section{An Ecosystem in Teachers Training}

The teaching to be an active agent increasingly has in your professional life to seek continuing education, as a precondition for upgrading the educational theories and practices experienced reflection. That said, being an educator requires new attitudes and practices, it is necessary to research, reflect, process, and construct knowledge (Torres et al., 2011).

Corroborates this statement Santos (2012: p. 17) stating that "in this context the continuing education favors the gradual and constant learning yourself (or self-learning) [...], as appropriate for each learner, respecting their learning style."

Continuing education requires a reflective dimension where:

[...] It needs to create networks of (self) training to enable understanding of the whole subject, taking the training as interactive and dynamic process. The exchange of experience and the sharing of knowledge consolidate spaces of mutual training in which every educator is called to simultaneously play the role of trainer and trainee (Nóvoa, 1995: p. 26).

Continued training, especially when related to insertion technologies in educational practices, to propose that those involved take a reflective attitude towards the teaching-learning process. Address the need for innovation focusing on integrating technology into the curriculum, having gone back to look at the context and the social conditions that influence, allows for a change of action in search of more significant results for you and the school community. Thus it is based:

The teacher professional development, in order to prepare them pedagogically to work with the plurality cognitive and experiential partner of the students through enrichment curricula to promote equality, peaceful coexistence, mutual learning, tolerance and social justice (Ferreira, 2006: p. 127).

For this study the focus will be on the experience of experts who carry out the continuing education of teachers of enhances adaptive ecosystem, we selected five trainers working in education and conduct ongoing training in different parts of Brazil, who answered the questionnaire Appendix A of this document.

Regarding Question 5- “How started the work with training for use of Aprimora?” there is a diversity of proposals, confirming that an adaptive ecosystem, have to take into account both the different ways of learning how to teach.

"Realized a conceptual product presentation explaining what it is, what's the point, how it works, scores, models, benefits and access". Leader 1

“Adaptive teaching concept and gamification”. Leader 2

"I think first it is important to treat the entire application of the concept, understanding of Adaptive Ecosystem for from that exploit resources and content”. Leader 4

“Demonstrating the importance of technology in an educational environment". Leader 5

In relation to Question 7 "The existence of different elements such as: digital resources, enhancement of learning styles, applying knowledge in real situations, the presentation of data on Aprimora, may provide a new way of organizing the curriculum? Tell us what you think...”. There is the answer of general trainers that the integration of technology into the curriculum happens gradually, but that the existence of an application with so many different elements, crucial to expand the possibilities for learning, as corroborate the following answers.

"Yes. From the collected reports can direct the college students targeted skills in a specific way". Leader 1 
(Bold of the authors)

"I think that these elements interfere directly in the teacher's planning. At least in private schools, planning is the crucial point for the use of tools". Leader 2 (Bold of the authors)

"They can and should be the reason for an immediate change in the curriculum. For motivating students is to use the language of technology for teachers is a support material ready and functional and managers a detailed records generator. But I understand that there is time to adapt to the use of funds and then resumes will be affected. This time could be minimized with accompaniment in the first moments of applications after training". Leader 3 (Bold of the authors)

"It provides a new way of curriculum organization in accordance with the possibilities that the application provides, as it gives autonomy to the teacher customize the application, either adding new content to complement the modules, either by changing the teaching strategy according to the need of each student, forwarding tasks is individualized according to the needs of each learner...”. Leader 4 (Bold of the authors) "One can not think about Aprimora in the distant teacher planning. I believe that the integration of technology with other learning tools are taken into consideration when these are available in the school environment. Teacher of the organization of all these possibilities in your curriculum that usually is already preset". Leader 5 (Bold of the authors)

The question 9 "The appropriation of technology in school culture can generate significant changes and pedagogical innovation, but such changes only occur when there is also a curriculum change. So the curriculum as a whole incorporates the language of the digital world.” Thinking about Aprimora and training of teachers who performs, you agree with this statement?

Regarding submitted claim (Q9), most participants expressed agree that the language of the digital world come to redesign the curriculum in its broad sense achieving more effective results in the teaching-learning process, as shown in the following answers.

"Yes. But a change in the culture of all the professionals of the institutions involved in the teaching and learning process is necessary". Leader 1 (Bold of the authors)

"Yes, but not enough to be just in the curriculum. It must be on the teacher's planning". Leader 2 (Bold of the authors)

"Not necessarily with the demand for change in the curriculum. Existing technology in schools are still beleaguered laboratories with no educational content desktops that are not included in the curriculum at most are used for research on the internet, and this is the moment of change. With the implementation (It is only then that I am present) of Aprimora, servers, interactive whiteboards and other resources, pedagogical changes already occur even not being implemented in $100 \%$ on the school curriculum. Some teachers start to use and others notice the benefits and so, gradually, the curriculum receives the inclusion of technologies. Ideally the inclusion in the curriculum and the immediate incorporation. That is, to be used with good results being incorporated ends not unlike, but in both cases causes raising and teaching innovation. Of course the correct and immediate inclusion in the curriculum would be more effective". Leader 3 (Bold of the authors)

"At least in the use of speech technology has been increasingly encouraged, but really only with a curriculum change and teacher training you can enter and work with technology in this educational context most effectively". Leader 4 (Bold of the authors)

"One cannot think of organizing a curriculum without considering all the tools, resources, tools that we have in our schools. The curriculum itself is premised consider all these factors that interact in your organization". Leader 5 (Bold of the authors)

It is found in the responses of trainers in general this application to be inserted in the dynamics of the classroom enables from continuing education, digital inclusion and gradually provides the possibility of developing a new, more comprehensive and effective curriculum to meet the demands of the students. The major advantages were observed by respondents in relation to the insertion of an application with adaptive ecosystem characteristics that aids in the integration technology/CV.

\section{Conclusion}

The way of living and producing in society is changing with the creation of computers, the Internet, wireless 
networks, cell phones and many other innovations that arise daily. To communication and access to information depended on a cable connection, it can now arise at any time or place in increasingly complete mobile devices.

This speed and changes in ways of living and coexisting also influence the forms of knowledge building. This reality brings up the questioning around the integration of technology into the curriculum that is waived by a restructuring of the demands in digital societies.

Increasing the production of devices and applications can help build the digital culture. In this sense, also emerging issues of education they need for reflection and theoretical support to subsidize the educational practices of teaching and learning in the digital world.

It presents the reflection of the assumptions related to adaptive ecosystem of Aprimora, by their characteristics help in practice, the integration of technology with the curriculum.

It is known that this process is long and deep, and its continuity character because of new knowledge arising from current educational practices in digital media, thus allowing the process to occur gradually and effectively. This reflection tends to be constant in the academic and educational institutions, as it arises from the need to analyze the implications of using technology in curriculum practices and ask which knowledge and practices redefine essentially prescriptive curriculum.

\section{References}

Capra, F. (1999). The Web of Life. Sao Paulo: Cultrix.

Cavellucci, B. C. L. (2006). Learning styles: In Search of Individual Differences. Http://www.Iar.Unicamp.Br/Disciplinas/Am540 2003/Lia/Estilos De Aprendizagem.Pdf

Felder, R. M. (1993). Reaching the Second Tier: Learning and Teaching Styles in College Science Education. Journal of College Science Teaching, 23. http://www4.ncsu.edu/unity/lockers/users/f/felder/public/Papers/Secondtier.html

Ferreira, W. B. (2006). In Educating Diversity: Inclusive Educational Practices in Regular. https://view.officeapps.live.com/op/view.aspx?src=http\%3A\%2F\%2Fsb576f10e3bce408d.jimcontent.com\%2Fdownload \%2Fversion\%2F1315362574\%2Fmodule\%2F4220467557\%2Fname\%2FEducar\%2520na\%2520diversidade-ensaiospedag ogicos.doc

Given, B. K. (2002). The Overlap between Brain Research and Research on Learning Style. In S. J. Armstrong et al. (Eds.), Learning Styles: Reliability \& Validity, Proceedings of the $7^{\text {th }}$ Annual Conference Elsin, Belgium \& Elsin, Ghent: Ghent University.

Kodu Game Lab (2014) http://www.kodugamelab.com/

Lévy, P. (1993). The Intelligence Technologies: The Future Thought in the Age of Information Technology (Translation C. I. da Costa, 2nd ed.). Rio De Janeiro: Editora 34.

Libâneo, J. C. (1985) Democratization of Public School: The Education Social Critic the Contents. Sao Paulo: Loyola.

Lindemann, V. (2008). Learning Styles: Seeking Synergy. Doctoral Thesis in Informatics Education, Porto Alegre: UFRGS.

Martín-Barbero, J. (2002) The Education since Communication: Latin American Encyclopedia Socioculture and Communication. Buenos Aires: Grupo Editorial Norma.

Nóvoa, A. (Ed.) (1995). The Teachers and Their Training (2nd ed.). Lisbon: Publications Don Quixote.

Pimentel, J. (1998). Reflections on the Qualities of Customization of Education. Http://www.Ipv.Pt/Millenium/Ect10_Pimtl.Htm

Santos, K. E. E. (2012). Collaborative in Distance Learning Education: A Way to The Continuing Education. Dissertation (Master of Education), Curitiba: Catholic University of Paraná.

Torres, P., Gubert, R., Kowalski, R., \& Tarrit, C. (2011) Program Agrinho: Use of Learning Objects for Distance Teacher education. http://educere.bruc.com.br/CD2011/pdf/6168_3801.pdf 


\section{Appendix A}

Hello,

My name is Katia Ethiénne dos Santos Esteves, do my doctorate degree at the Catholic University of Paraná and along with my supervisor Prof. PhD Patricia Torres Lupion invite you to participate in this research referring to Improve Primary Education telling us a little about your experience.

Data:

The inclusion of your name is optional:

1. Characterization

1.1. Gender: Men. ( ) Fem. ( )

1.2. Age:

2. Job

2.1. Current position holds:

2.2. How long have you been in your current role?

3. Education

Graduation: ( ) completed ( ) attending What curse?

Post graduation:__ Specialization:

Master: ( ) complete ( ) attending what theme?

Doctoral: ( ) complete ( ) attending what theme?

4. During the formation of Improves

4.1. You worked with the two subject areas: Mathematics and Portuguese Language?

Yes ( )

No ( )

4.2. Tell us what levels which addressed:

4.3. And which module has most used?

5. As the work began with training for use of the Improve?

6. What are the issues related to training for using Enhances who believe are the most relevant?

7. The existence of different elements such as: digital resources, enhancement of learning styles, applying knowledge in real situations, the presentation of data on Enhances may provide a new way of organizing the curriculum? Tell us what you think...

8. Do you believe that an application such as Enhances can offer the educational environment improve the quality of teaching-learning process? Because? 
9. "The appropriation of technology in school culture can generate significant changes and pedagogical innovation, but such changes only occur when there is also a curriculum change. So the curriculum as a whole incorporates the language of the digital world." Enhances the thinking and training of teachers who performs, you agree with that statement?

10. In relation to Improve, an adaptive ecosystem that enables: differentiated learning, motivation through gamification features, monitoring of performance data of students and the possibility of changing teaching strategies according to individual or group needs. write as you have inserted in their formations the idea of collaboration in the teaching-learning process (students and teachers, teachers and professors, students and students).

Thank you for your collaboration and we are committed to send you the resulting document this data collection. Best regards, Katia Ethiénne Esteves dos Santos 